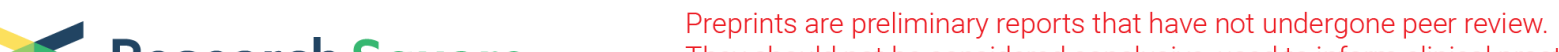 Research Square They should not be considered conclusive, used to inform clinical practice, or referenced by the media as validated information.
}

\section{A Case of Colonic Micropapillary Carcinoma With a High Frequency of Apoptosis}

\section{Kazumori Arai ( $\nabla$ m-arai@ny.tokai.or.jp )}

Shizouka General Hospital

\section{Tomohiro Iwasaki}

Shizouka General Hospital

Hisato Ishimatsu

Shizouka General Hospital

Chinatsu Tsuchiya

Shizouka General Hospital

Aki Kubota

Shizouka General Hospital

Akihiro Sonoda

Shizouka General Hospital

Ko Ohata

Shizouka General Hospital

\section{Research Article}

Keywords: apoptosis, colorectal cancer, immunohistochemistry, micropapillary carcinoma, tumor budding

Posted Date: April 15th, 2021

DOI: https://doi.org/10.21203/rs.3.rs-401857/v1

License: (c) (i) This work is licensed under a Creative Commons Attribution 4.0 International License.

Read Full License

Version of Record: A version of this preprint was published at Journal of Gastrointestinal Cancer on July 24th, 2021. See the published version at https://doi.org/10.1007/s12029-021-00674-2. 


\section{Abstract}

Purpose: Colorectal micropapillary carcinoma (MPC) exhibits aggressive biological characteristics, with empty spaces and reversed polarity, similar to the poorly differentiated clusters (PDCs) formed from detached cancer cells. Epithelial-mesenchymal transition, which is involved in the cancer cell acquisition of apoptosis resistance, is closely linked with histological findings of MPC, PDCs, and tumor buds (TBs), with MPC and TBs considered as apoptosis-resistant features. However, we encountered a case of colonic MPC with frequent apoptosis.

Methods: We examined the case using immunohistochemistry and compared it with two cases of conventional colonic cancer with high PDC and TB presence.

Results: In many of the tumor glands (TGs) of the MPC, empty spaces and tumor cell detachment toward the gland interior were observed. Moreover, TG ruptures were scattered, with PDCs adjacent to them. Apoptosis occurred mainly at the TG and PDC peripheries in the middle and deep tumor layers, and transforming growth factor beta 1 (TGF- $\beta 1$ ) positivity was evident in those tumor cells. Cells positive for apoptosis-related M30 were distributed mainly in the deep layer with a significant PDC and TB presence. However, apoptosis and M30 positivity were low in the TBs. In the control cases, apoptosis hardly occurred. Furthermore, M30 positivity in the TGs was scattered and barely evident in the PDCs. Aberrant $\beta$-catenin positivity was found. In MPC, non-tumorous bud components, especially those in the deep layer, had poor abilities to promptly acquire apoptosis resistance.

Conclusion: Apoptosis has the potential to reciprocally produce MPC, PDCs, and TBs, with TGF- $\beta 1$ involvement.

\section{Introduction}

Micropapillary carcinoma (MPC) of the colon, an uncommon subtype of colorectal cancer (CRC), generally coexists with components of conventional adenocarcinoma (AC) [1-4]. MPC of the colon or rectum, like that of various other organs, is known to display aggressive biological characteristics, such as lymphovascular invasion and node metastasis, and generally has a poor prognosis [2-5]. Additionally, regardless of the primary organ, MPC is characterized by neoplastic cell clusters that are located in empty spaces, resemble dilated lymphatic vessels, and show reversed polarity (i.e., inside-out structures) [1-5]. In CRC, poorly differentiated clusters (PDCs) are a tumor feature that has much in common with the clinicopathological and morphological characteristics of MPC [6-8], and the two structures may overlap pathogenetically [6-8]. PDCs, which are formed from cancer cells that have detached from a main tumor body, are defined as clusters of five or more neoplastic cells without glandular formation [8, 9]. A similar feature consisting of less than five neoplastic cells is the tumor bud (TB) [10], which represents a morphological continuum with the PDC [7-10] and also exhibits similar characteristics as colorectal MPC and PDCs (MPC/PDCs) [7, 8]. In fact, because of their clinicopathological and morphological similarities, colorectal MPC/PDCs and TBs are considered to be sequential growth patterns that branch from 
common biological processes [7], with PDC formation being regarded as the step prior to tumor budding [11].

Colorectal MPC/PDCs and TBs are considered to be closely linked with epithelial-mesenchymal transition (EMT) $[4,6,7,12-14]$. In general, cancer cells that have undergone EMT acquire resistance to apoptosis, have a higher invasive capacity, and exhibit aggressive biological behavior $[15,16]$. This observation is supported by reports that the TBs of CRC display apoptosis resistance, unlike the conventional AC components $[17,18]$. Moreover, micropapillary structures have been shown to be one of the putative apoptosis-resistant subpopulations in CRC $[19,20]$. Studies have also shown that KRAS mutations are related to the development of colorectal MPC/PDCs and TBs and are involved in the acquisition of apoptosis resistance by cancer cells $[4,18,21,22]$. However, in contrast to these reports, we have encountered a case of colorectal MPC with frequent apoptosis (herein case 1). The tumor in this patient had many PDCs and also showed a high degree of tumor budding. Therefore, we examined the relationship between apoptosis and MPC/PDCs or TBs in the tumor with the unique histological findings. For comparison, we also examined our two previously reported cases of conventional CRC with high TB and PDC presence [23] (herein case 2 and case 3, respectively). In this study, immunohistochemistry was performed using antibodies against M30 CytoDEATH (M30) (an apoptosis-related marker) [17, 19, 20, 24, 25], epithelial membrane antigen (EMA) (the gold-standard marker for luminal differentiation) $[2,3,7,25$, 26], and transforming growth factor beta 1 (TGF- $\beta 1$ ), E-cadherin, and $\beta$-catenin (the latter three all EMTrelated markers) $[6,7,12-14,27-32]$. This case highlights the fact that much about apoptosis and its relation to cancer pathology remains to be elucidated.

\section{Case Histories}

Case 1

A 77-year-old woman presented with bloody stool that had persisted for the last 3 months. A colonoscopy revealed an ulcerated tumor in the sigmoid colon. She had a history of 15 years with diabetes mellitus and 7 years with chronic heart failure and atrial fibrillation, but she had neither a medical nor a family history of cancer. No metastases to the lymph nodes or other organs could be detected upon various imaging examinations, including computed tomography. With regard to tumor markers, the carcinoembryonic antigen (CEA) and cancer antigen 19-9 (CA-19-9) levels were within the normal range at $2.9 \mathrm{ng} / \mathrm{ml}$ (normal range $0-5 \mathrm{ng} / \mathrm{ml}$ ) and less than $1.0 \mathrm{U} / \mathrm{ml}$ (normal range $0-37 \mathrm{U} / \mathrm{ml}$ ), respectively. Because the colonoscopic biopsy revealed an AC, laparoscopic sigmoidectomy and lymph node dissection were performed. No analyses for mismatch repair (MMR) and the KRAS mutation status were performed. According to her medical history, she did not receive adjuvant therapy. Although the patient did not experience recurrence during the follow-up period of 16 months after surgery, she died suddenly of heart failure. An autopsy was not performed.

Case 2 
The detailed clinical course of this patient has been described elsewhere [23]. In brief, the patient was a 70-year-old woman with sub-circumferential ulcerated colon cancer. After surgery, the patient received XELOX (oxaliplatin in combination with capecitabine) for 3 months. The tumor showed proficient MMR. The KRAS mutation status was not analyzed. In spite of subsequent chemotherapy being discontinued, the patient did not experience recurrence during the follow-up period.

\section{Case 3}

The detailed clinical course of this patient has been described elsewhere [23]. In brief, the patient was a 65-year-old man with circumferential ulcerated colon cancer. After surgery, the patient received chemotherapy (XELOX or capecitabine only) for 5.5 months. Twelve months after surgery, multiple metastases were detected. The tumor exhibited proficient MMR. There were no KRAS mutations found. The patient received chemotherapy with combination FOLFILI (5-fluorouracil combined with levofolinate and irinotecan) and panitumumab or FOLFIRI (folinic acid, 5-fluorouracil, and irinotecan) alone for 16 months. The metastases were partially reduced, and the patient survived 30 months after surgery.

Three representative tissue sections, including both the tumor center and the tumor margin, were examined for each patient case. TB or PDC scoring, with count correction for the objective lens, was performed as described elsewhere [9,10,23]. Immunohistochemistry for podoplanin (D2-40) (a lymphatic vessel marker with a key role in cell invasiveness), M30, EMA, TGF- $\beta 1$, E-cadherin, and $\beta$-catenin was carried out on serial tissue sections, using the Leica Bond-Max system (Leica Biosystems, Melbourne, Australia). The mouse anti-human D2-40 antibody (clone D2-40, ready to use, Nichirei Bioscience, Tokyo, Japan) was applied after subjecting the tissue sections to heat-induced antigen retrieval in a citratebased solution ( $\mathrm{pH} \mathrm{6.0)} \mathrm{for} 20 \mathrm{~min}$. Since this antibody reacts with the lymphatic endothelium, it is commonly used to distinguish between lymphatic vessels and empty spaces around tumor components $[3,6]$. The conditions used for staining M30 and EMA are described elsewhere [25]. M30 detects apoptotic glandular-epithelial and AC cells through its recognition of a specific epitope of cytokeratin 18 [24] and is considered more specific and reliable than the TUNEL assay [24]. This antibody is often used for immunohistochemical studies of apoptosis resistance in AC $[17,19,20]$. EMA is used for the immunohistochemical demonstration of structures with reversed polarity $[2,3,7,25,26]$. The rabbit TGF$\beta 1$ polyclonal antibody (Proteintech Japan, Tokyo, Japan) [33] and mouse anti-human E-cadherin antibody (clone NCH-38, DAKO, Carpinteria, CA, USA), both used at a dilution ratio of 1:200, were applied to tissue sections that had been subjected to heat-induced antigen retrieval in an ethylenediaminetetraacetic acid-based solution $(\mathrm{pH} 9.0)$ for $20 \mathrm{~min}$. The mouse anti-human $\beta$-catenin antibody (clone 17C2, Leica Microsystems, Newcastle Upon Tyne, Tyne and Wear, UK) was used at a 1:100 dilution ratio on tissue sections that had undergone heat-induced antigen retrieval in a citratebased solution ( $\mathrm{pH} \mathrm{6.0)}$ for $30 \mathrm{~min}$. As a key event of EMT, the well-known dissolution of epithelial junctions is represented by the activation of signaling pathways via receptor proteins, such as TGF- $\beta$ and Wnt [27, 28, 30, 32]. In colonic MPC, PDCs, and TBs, the aberrant expression of E-cadherin and $\beta$-catenin has been indicated $[3,6,7,12-14]$. The E-cadherin and $\beta$-catenin immunoreactivities of the tumor tissue sections were compared with those of the cryptal epithelium in the noncancerous part, respectively [34]. 


\section{Routine pathological findings}

Case 1

Macroscopic examination revealed an ulcerated tumor measuring $2.2 \times 2.6 \mathrm{~cm}$ (Fig. 1a). Microscopically, the tumor invaded the subserosa, but no serosal exposure was noted. The tumor consisted mainly of PDCs with empty spaces (Fig. 1b); furthermore, although the glandular growth pattern of the AC was mixed, it decreased toward the invasion front (Fig. 1c). In many of the tumor glands (TGs), tumor cell detachment from the stroma toward the gland interior was observed as well as various-sized empty spaces (Fig. 1d). Furthermore, the destruction of the glandular structures was scattered, and PDCs were found near the ruptured ones (Fig. 1d). In the deep layer of the tumor, especially at the invasion front, small PDCs composed of ten or less cancer cells and TBs were scattered (Fig. 2a), regardless of the tumor center and the tumor margin. PDCs and TBs were also found in the upper and middle layers of the tumor (Fig. 1c). However, when they were counted in 30 microscopic fields (10 fields each per section), each in the upper and middle layers and in the deep layer, including the invasion front, they were found to be predominant in the deep layer [interquartile ranges for upper and middle layers vs. deep layer: PDCs, 6.0 (4.0-9.0) vs. 12.0 (10.0-13.0), $P<0.0001$; TBs, 3.0 (2.0-4.0) vs. 6.0 (5.0-8.8), $P<0.0001]$. The analyses were performed by Mann-Whitney U-test using EasyR (EZR) on R commander (version 1.41) (Division of Hematology, Saitama Medical Center, Jichi Medical University, Saitama, Japan). The maximum numbers of PDCs and TBs were 17 and 13 per field, respectively, and each number corresponded to a score of $3[9,10]$, with the PDCs being predominant. The tumor metastasized to six regional lymph nodes, corresponding to pathological stage IIIB (pT3N2aM0) [35].

Notably, apoptotic cells and bodies were scattered in the TGs as were non-small-sized PDCs in the middle and deep layers of the tumor (Fig. 2b). Additionally, many of their empty spaces also contained apoptotic cells and bodies, and some of the spaces showed septum-like structures, representing a concentrated vacuole-like appearance (Fig. 2b).

\section{Case 2}

The detailed findings regarding the TBs and PDCs in the tumor of this patient are described elsewhere [23]. In this present study, findings on apoptosis were added. Small PDCs and TBs were found in the invasion front (Fig. 3a), with the maximum numbers of 12 and 22 per field, respectively. Each number corresponded to a score of $3[9,10]$, and the TBs were predominant. In the TGs giving rise to TBs and PDCs, the tumor cells protruded into the stroma in a cord-like appearance (Fig. 3a). Furthermore, partial empty spaces with septum-like structures (Fig. 3a) and a small amount of apoptotic cells were found. However, apoptotic cells and bodies were barely evident in the PDCs and TBs. The tumor metastasized to five regional lymph nodes, corresponding to pathological stage IIIB (pT3N2aM0) [35].

\section{Case 3}


Detailed findings regarding the TBs and PDCs in the tumor of this patient are described elsewhere [23]. Findings on apoptosis were added in this present study. Many PDCs and TBs were distributed around the conventional AC components in the invasion front and inside the tumor (Fig. 3b). The maximum numbers of PDCs and TBs were 21 and 15 per field, respectively. Each number corresponded to a score of $3[9,10]$, with the PDCs being predominant. Both of these tumor structures had partial or circumferential empty spaces (Fig. 3b). In some of the TGs, tumor cell detachment from the stroma toward the gland interior was evident along with empty spaces and disruption of the glandular structure (Fig. 3b). PDCs were found near the ruptured TGs (Fig. 3b). Apoptotic cells and bodies were observed in the TBs and PDCs, albeit only a few. The tumor metastasized to four regional lymph nodes, corresponding to pathological stage IIIC (pT4aN2aM0) [35].

\section{Immunohistochemical findings}

D2-40

In all three cases, most of the empty spaces were negative for D2-40, indicating the absence of lymphatic vessels.

M30

\section{Case 1}

The M30-positive parts were distributed predominantly in the deep layer of the tumor, in a band-like appearance (Fig. 4a), whereas their distribution in the upper layer was minimal (Fig. 4a). Furthermore, they were located mainly at both the peripheries of the TGs and large PDCs and within their empty spaces and consisted of cells and granules (probably apoptotic cell debris) of various sizes (Fig. 4b). Some of the M30-positive parts within the empty spaces partially rimmed the individual vacuoles (Fig. 4c). In the small PDCs and TBs, the M30-positive parts were diminished and barely evident, especially in the TBs (Fig. 4d). The same was true for the TBs in the upper and middle layers of the tumor.

\section{Case 2}

In the PDCs, TBs, and protruding tumor cells of the TGs, only a few M30-positive granules were found (Fig. 5a). By contrast, positive reactions were scattered among the non-protruding tumor cells, even in the TGs with TBs and PDCs (Fig. 5a). No distinct M30 positivity was observed within their empty spaces (Fig. $5 a)$.

\section{Case 3}

Positive antibody reactions were evident among the tumor cells in the TGs giving rise to TBs and PDCs, whereas M30 positivity was hardly found in the PDCs and TBs (Fig. 5b). No distinct positivity was observed within their empty spaces (Fig. 5b). 


\section{Case 1}

The PDCs showed linear positivity for EMA at the stroma-facing surfaces, but most of the positivity was not circumferential (Fig. 6a). Even in the TGs that partially lacked contact with the stroma, linear positivity was found at the stroma-facing surfaces of the detached tumor cells as well as at their luminal surfaces (Fig. 6b). By contrast, linear positivity for EMA was weak in the small PDCs and TBs.

\section{Case 2}

Except for some of the luminal surfaces, no distinct linear positivity for EMA could be found.

\section{Case 3}

The results were almost the same as those of case 1.

TGF- $\beta 1$

\section{Case 1}

In both the TGs with empty spaces and the PDCs, granular cytoplasmic positivity for TGF- $\beta 1$ was found (Fig. 7a). The positivity in those tumor components was observed, regardless of their locations, both states (cells or granules), and amount of M30-positive parts. By contrast, the TBs showed only faint positivity. Inflammatory cells, including neutrophils and macrophages, also showed cytoplasmic positivity for this transcription factor (Fig. 7a).

\section{Case 2}

In all of the tumor components, including PDCs and TBs, only faint cytoplasmic positivity for TGF- $\beta 1$ was evident (Fig. 7b).

\section{Case 3}

The results were basically the same as those of case 1 (Fig. 7c).

E-cadherin

\section{Case 1}

The PDCs and TBs displayed marked reductions in their membranous positivity for E-cadherin, showing a dot-like appearance. Some of the TBs showed loss of the positivity. In TGs with empty spaces, the membranous positivity was moderately diminished.

\section{Case 2}

In the PDCs, TBs, and protruding tumor cells of the TGs, moderate to marked reductions in the membranous positivity for E-cadherin were found. Some of the TBs showed a loss of the positivity. 
Case 3

In the TGs with empty spaces and in many of the PDCs and TBs, the diminution in the membranous positivity was mild to moderate. However, in some of the tumor cells, a marked reduction or loss of the positivity was found.

$\beta$-catenin

Case 1

The PDCs and TBs displayed marked reductions in their membranous positivity for $\beta$-catenin, showing a dot-like appearance (Fig. 8a). Some of the TBs showed a loss of the positivity. However, no nuclear positivity was evident in any of the tumor cells (Fig. 8a). In the TGs with empty spaces, the membranous positivity was moderately diminished.

Case 2

In the PDCs, TBs, and TGs giving rise to TBs and PDCs, the membranous positivity for $\beta$-catenin was barely evident, whereas nuclear positivity for the protein was scattered (Fig. 8b).

\section{Case 3}

In the PDCs, TBs, and TGs giving rise to TBs and PDCs, diffuse cytoplasmic positivity for $\beta$-catenin was evident, but membranous positivity was barely observed (Fig. 8c). Moreover, some of those tumor cells showed nuclear positivity for this protein (Fig. 8c).

\section{Discussion}

In all three cases, the distribution of M30-positive cells was not uniform, and there were differences depending on the morphology of the tumor components. Common to all three cases, M30 positivity was scattered in the TGs, and that in the TBs was the least among the tumor components. The TBs were considered to be the tumor component that had acquired the most apoptosis resistance, which was in line with previous reports $[17,18]$. In case 1 , PDCs were also observed in the upper and middle layers of the tumor i.e., in an old lesion in which tumorigenesis had occurred. However, there were fewer M30positive cells in the old lesion than in the deep layer of the tumor i.e., in a lesion newer than the upper and middle layers of the tumor. It is possible that at least some of the PDCs in the old lesion had acquired apoptosis resistance $[17,20]$. These findings above suggest that the results of M30 immunostaining reflect the different stages in the apoptosis resistance-acquiring process of the tumor cells. In both case 2 and case 3 , the tumor cells are considered to have already acquired apoptosis resistance at an early stage of TB and PDC development $[17,18,20]$. By contrast, the PDCs in the deep layer of the tumor in case 1 had a poor ability to promptly acquire apoptosis resistance $[17,20]$. 
In case 1, apoptosis was also scattered at the periphery of the TGs. We had previously reported a case of invasive mammary MPC with frequent apoptosis, which suggested the involvement of the apoptotic process in the formation of a micropapillary pattern in cancers [25]. The TGs of the mammary MPC had the following pathological findings in common with those of the colonic MPC in case 1: scattered tumor cell detachment from the stroma toward the gland interior; scattered empty spaces, including apoptotic cells and bodies; and M30-positive vacuoles within the empty spaces, suggesting its derivation from a secondary necrosis followed by apoptosis [25,36]. In our previous report of invasive mammary MPC [25], we considered that apoptosis is involved in the formation of a micropapillary pattern by the following mechanisms: 1) both frequent apoptosis and secondary necrosis disturb the apical-basal polarity of the tumor cells everywhere, resulting in a condition resembling to partially polarized structures with dysplastic features [37]; 2) in the state where the basal polarity was lost due to cell detachment, even detached tumor cells without luminal differentiation might acquire an apical polarity on the stromafacing surface, under the effects of cell-cell contacts with the neighboring tumor cells with an apical polarity [37]; 3) secondary necrosis of the apoptotic tumor cells with luminal differentiation has the potential to partially create detached tumor cells with reverse polarity $[36,37]$. In general, cells detached from the surrounding stroma fall into apoptosis [15]. In case 1, it is likely that tumor cell detachment had occurred sporadically in many TGs as a result of some unknown factor(s), resulting in frequent apoptosis [15]. Additionally, it is possible that progressive cell detachment and the subsequent disruption of the glandular structure, attributed to frequent apoptosis, caused a loss of apical-basal polarity, and the connection between the luminal surface and the stroma-facing surface, in the tumor cells of the TG, resulting in the formation of PDCs within the empty spaces [25]. In the deep layer of the tumor in case 1, further tumor cells may have shaved off from the PDCs that had a poor ability to promptly acquire apoptosis resistance, resulting in the production of smaller PDCs and more TBs $[17,20,25]$. Taken together, the results suggest that although apoptosis is generally regarded as a cellular phenomenon that functions contrary to MPC/PDCs and TBs [17-20], it could in fact potentially reciprocally produce these three tumor features [25].

In case 1, TGF- $\beta 1$ also has the potential to be related to the occurrence of MPC/PDCs. By contrast, nuclear $\beta$-catenin signaling is unlikely to be activated, despite the marked reduction in the membranous expression of both E-cadherin and $\beta$-catenin. However, this deficiency in nuclear $\beta$-catenin expression is consistent with that in a previous report [3]. The TGF- $\beta$ pathway plays an important role in orchestrating the EMT mechanisms $[27,28,32]$ and is also involved in the downregulation of membranous E-cadherin $[27,28]$. TGF- $\beta$ also activates several downstream pathways mediated by effectors and/or transcription factors other than $\beta$-catenin $[27,28,32]$. Additionally, although TGF- $\beta 1$ is known to induce apoptosis resistance in cells, thereby triggering the loss of cell polarity attributed to apoptosis, it has also been shown to promote the apoptotic process, indicating its dual functions with regard to this cell death phenomenon [38-40]. In case 2, nuclear $\beta$-catenin signaling is possibly involved in the occurrence of TBs and PDCs, which is in line with previous reports on these tumor components in CRC [12-14]. Conversely, TGF- $\beta 1$, whether through the autocrine or paracrine secretion from the tumor cells themselves [41], is 
considered to be less involved in the occurrence of TBs and PDCs in this case. By contrast, TGF- $\beta$ and nuclear $\beta$-catenin signaling are possibly involved in the occurrence of TBs and PDCs in case $3[12-14,41]$.

This case report has some limitations, including the limited conclusive relationships that can be drawn through TGF- $\beta 1$, E-cadherin, and $\beta$-catenin immunostaining alone and the intrinsic limitations of a case report. Further investigations are needed to confirm our suppositions.

In conclusion, we have described a case of MPC with frequent apoptosis that occurred mainly in the deep layer of the tumor where significantly higher numbers of TBs and PDCs were evident. The tumor components in the area appeared to have a poor ability to acquire apoptosis resistance promptly $[17,20]$. This case highlights that much is still not known about the role that apoptosis plays in the pathology of cancer. Whereas most studies have pointed to the fact that MPC and TBs are simply apoptosis-resistant tumor features, this case suggests that apoptosis has the potential to reciprocally produce MPC/PDCs and TBs through the involvement of TGF- $\beta 1$ [38-41].

\section{Declarations}

\section{Funding}

This report received no specific grant from any funding agency in the public, commercial, or not-for-profit sectors.

\section{Conflict of interest}

The authors declare no conflicts of interest regarding the publication of this article.

\section{Availability of data and materials}

The authors declare that all relevant data are included in this published article and are available within the paper.

\section{Code availability}

Not applicable

\section{Authors' contributions}

All authors were involved in the preparation of this manuscript. KA designed the study and wrote the initial draft of the manuscript. TI, CT, and AK contributed to analysis and interpretation of immunohistochemical data. HI, AS, and KO contributed to analysis and interpretation of clinical data and to obtaining informed consent from patients. All authors read and approved the final version of the manuscript.

\section{Ethics approval}


This case report was approved by the Ethics committee of Shizuoka General Hospital (approval number: SGH IRB\#2018091/1).

\section{Consent to participate}

Written informed consent was obtained from the patient.

\section{Consent to publish}

Written informed consent to publish the case details was obtained from the patient.

\section{References}

1. WHO classification of tumours editorial board, editors (2018) WHO Classification of Tumours 5th Edition. Lyon, France, pp 181.

2. Verdu M, Roman R, Calvo M, Rodón N, García B, González M, Vidal A, Puig X (2011) Clinicopathological and molecular characterization of colorectal micropapillary carcinoma. Mod Pathol 24:729-738. https://doi.org/10.1038/modpathol.2011.1

3. Guzinska-Ustymowicz K, Niewiarowska K, Pryczynicz A (2014) Invasive micropapillary carcinoma: a distinct type of adenocarcinoma in the gastrointestinal tract. World J Gastroenterol 20:4597-4606. https://doi.org/10.3748/wjg.v20.i16.4597

4. Gonzalez RS, Huh WJ, Cates JMM, Washington K, Beauchamp RD, Coffey RJ, Shi C (2017) Micropapillary colorectal carcinoma: clinical, pathological and molecular properties, including evidence of epithelial-mesenchymal transition. Histopathology 70:223-231. https:// doi.org/10.1111/his. 13068

5. Nassar H, Pansare V, Zhang H, Che M, Sakr W, Ali-Fehmi R, Grignon D, Sarkar F, Cheng J, Adsay V (2004) Pathogenesis of invasive micropapillary carcinoma: role of MUC1 glycoprotein. Mod Pathol 17:1045-1050. https:// doi.org/ 10.1038/modpathol.3800166

6. Barresi V, Branca G, Vitarelli E, Tuccari G (2014) Micropapillary pattern and poorly differentiated clusters represent the same biological phenomenon in colorectal cancer: a proposal for a change in terminology. Am J Clin Pathol 142:375-383. https://doi.org/10.1309/AJCPFEA7KA0SBBNA

7. Hong M, Kim JW, Shin MK, Kim BC (2017) Poorly differentiated clusters in colorectal adenocarcinomas share biological similarities with micropapillary patterns as well as tumor buds. $J$ Korean Med Sci 32:1595-1602. https://doi.org/10.3346/jkms.2017.32.10.1595

8. Shivji S, Conner JR, Barresi V, Kirsch R (2020) Poorly differentiated clusters in colorectal cancer: a current review and implications for future practice. Histopathology 77:351-368. https://doi.org/10.1111/his.14128

9. Ueno H, Kajiwara Y, Shimazaki H, Shinto E, Hashiguchi Y, Nakanishi K, Maekawa K, Katsurada Y, Nakamura T, Mochizuki H, Yamamoto J, Hase K (2012) New criteria for histologic grading of colorectal cancer. Am J Surg Pathol 36:193-201. https://doi.org/10.1097/PAS.0b013e318235edee 
10. Lugli A, Kirsch R, Ajioka Y, Bosman F, Cathomas G, Dawson H, El Zimaity H, Fléjou JF, Hansen TP, Hartmann A, Kakar S, Langner C, Nagtegaal I, Puppa G, Riddell R, Ristimäki A, Sheahan K, Smyrk T, Sugihara K, Terris B, Ueno H, Vieth M, Zlobec I, Quirke P (2017) Recommendations for reporting tumor budding in colorectal cancer based on the international tumor budding consensus conference (ITBCC) 2016. Mod Pathol 30:1299-1311. https://doi.org/10.1038/modpathol.2017.46

11. Yang M, Rehman AU, Zuo C, Sheehan CE, Lee EC, Lin J, Zhao Z, Choi E, Lee H (2016) A novel histologic grading scheme based on poorly differentiated clusters is applicable to treated rectal cancer and is associated with established histopathological prognosticators. Cancer Med 5:15101518. https://doi.org/10.1002/cam4.740

12. Grigore AD, Jolly MK, Jia D, Farach-Carson MC, Levine H (2016) Tumor budding: the name is EMT. partial EMT. J Clin Med 5:51. https://doi.org/10.3390/jcm5050051

13. Bertoni L, Barresi V, Bonetti LR, Caramaschi S, Mangogna A, Lionti S, Azzoni P, Carnevale G, Pisciotta A, Salviato T (2019) Poorly differentiated clusters (PDC) in colorectal cancer: does their localization in tumor matter? Ann Diagn Pathol 41:106-111. https://doi.org/10.1016/j.anndiagpath.2019.06.008

14. Lugli A, Zlobec I, Berger MD, Kirsch R, Nagtegaal ID (2021) Tumour budding in solid cancers. Nat Rev Clin Oncol 18:101-105. https://doi.org/10.1038/s41571-020-0422-y

15. Frisch SM, Schaller M, Cieply B (2013) Mechanisms that link the oncogenic epithelial-mesenchymal transition to suppression of anoikis. J Cell Sci 126:21-29. https://doi.org/10.1242/jcs.120907

16. Paoli P, Giannoni E, Chiarugi P (2013) Anoikis molecular pathways and its role in cancer progression. Biochim Biophys Acta 1833:3481-3498. https://doi.org/10.1016/j.bbamcr.2013.06.026

17. Dawson H, Koelzer VH, Karamitopoulou E, Economou M, Hammer C, Muller DE, Lugli A, Zlobec I (2014) The apoptotic and proliferation rate of tumour budding cells in colorectal cancer outlines a heterogeneous population of cells with various impacts on clinical outcome. Histopathology 64:577584. https://doi.org/10.1111/his.12294

18. Dawson H, Grundmann S, Koelzer VH, Galván JA, Kirsch R, Karamitopoulou E, Lugli A, Inderbitzin D, Zlobec I (2015) Tyrosine kinase receptor B (TrkB) expression in colorectal cancers highlights anoikis resistance as a survival mechanism of tumour budding cells. Histopathology 66:715-725. https://doi.org/10.1111/his.12603

19. Patankar M, Väyrynen S, Tuomisto A, Mäkinen M, Eskelinen S, Karttunen TJ (2018) Micropapillary structures in colorectal cancer: an anoikis-resistant subpopulation. Anticancer Res 38:2915-2921. https://doi.org/10.21873/anticanres.12539

20. Patankar M, Mattila T, Väyrynen JP, Klintrup K, Mäkelä J, Tuomisto A, Nieminen P, Mäkinen MJ, Karttunen TJ (2020) Putative anoikis-resistant subpopulations in colorectal carcinoma: a marker of adverse prognosis. APMIS 128:390-400. https://doi.org/10.1111/apm.13041

21. Barresi V, Bonetti LR, Bettelli S (2015) KRAS, NRAS, BRAF mutations and high counts of poorly differentiated clusters of neoplastic cells in colorectal cancer: observational analysis of 175 cases. Pathology 47:551-556. https://doi.org/10.1097/PAT.0000000000000300 
22. Patankar M, Eskelinen S, Tuomisto A, Mäkinen MJ, Karttunen TJ (2019) KRAS and BRAF mutations induce anoikis resistance and characteristic 3D phenotypes in Caco-2 cells. Mol Med Rep 20:46344644. https://doi.org/10.3892/mmr.2019.10693

23. Arai K, Ishimatsu H, Iwasaki T, Tsuchiya C, Sonoda A, Ohata K (2020) Membranous S100A10 involvement in the tumor budding of colorectal cancer during oncogenesis: report of two cases with immunohistochemical analysis. World J Surg Oncol 18:289. https://doi.org/10.1186/s12957-02002075-4

24. Duan WR, Garner DS, Williams SD, Funckes-Shippy CL, Spath IS, Blomme EAG (2003) Comparison of immunohistochemistry for activated caspase-3 and cleaved cytokeratin 18 with the TUNEL method for quantification of apoptosis in histological sections of PC-3 subcutaneous xenografts. J Pathol 199:221-228. https://doi.org/10.1002/path.1289

25. Arai K, Iwasaki T, Tsuchiya C, Sonoda A (2020) Involvement of annexin A2 expression and apoptosis in reverse polarization of invasive micropapillary carcinoma of the breast. Case Reports in Pathol 2020:9242305. https://doi.org/10.1155/2020/9242305

26. Cserni G (2014) Reversed polarity of the glandular epithelial cells in micropapillary carcinoma of the large intestine and the EMA/MUC1 immunostain. Pathology 46:527-532. https://doi.org/10.1097/PAT.0000000000000144

27. Thiery JP, Acloque H, Huang RYJ, Nieto MA (2009) Epithelial-mesenchymal transitions in development and disease. Cell 139:871-90. https://doi.org/10.1016/j.cell.2009.11.007

28. Lamouille S, Xu J, Derynck R (2014) Molecular mechanisms of epithelial-mesenchymal transition. Nat Rev Mol Cell Biol 15:178-96. https://doi.org/10.1038/nrm3758

29. Jensen DH, Dabelsteen E, Specht L, Fiehn AM, Therkildsen MH, Jønson L, Vikesaa J, Nielsen FC, von Buchwald C (2015) Molecular profiling of tumour budding implicates TGF $\beta$-mediated epithelialmesenchymal transition as a therapeutic target in oral squamous cell carcinoma. J Pathol 236:50516. https://doi.org/10.1002/path.4550

30. Smedt LD, Palmans S, Sagaert X (2016) Tumour budding in colorectal cancer: what do we know and what can we do? Virchows Arch 468:397-408. https://doi.org/10.1007/s00428-015-1886-5

31. Soleimani A, Pashirzad M, Avan A, Ferns GA, Hassanian SM (2019) Role of the transforming growth factor- $\beta$ signaling pathway in the pathogenesis of colorectal cancer. J Cell Biochem 120:8899-8907. https://doi.org/10.1002/jcb.28331

32. Dongre A, Weinberg RA (2019) New insights into the mechanisms of epithelial-mesenchymal transition and implications for cancer. Nat Rev Mol Cell Biol 20:69-84. https://doi.org/10.1038/s41580-018-0080-4

33. Gu C, Wang X, Long T, Wang X, Zhong Y, Ma Y, Hu Z, Li Z (2018) FSTL1 interacts with VIM and promotes colorectal cancer metastasis via activating the focal adhesion signalling pathway. Cell Death Dis 9:654. https://doi.org/10.1038/s41419-018-0695-6

34. Hugh TJ, Dillon SA, Taylor BA, Pignatelli M, Poston GJ, Kinsella AR (1999) Cadherin-catenin expression in primary colorectal cancer: a survival analysis. Br J Cancer 80:1046-1051. 
https://doi.org/10.1038/sj.bjc.6690461

35. Brierley JD, Gospodarowicz MK, Wittekind C (2017) Union for International Cancer Control (UICC): TNM Classification of Malignant Tumours. 8th edn. John Wiley \& Sons, New Jersey, pp 73-76.

36. Zhang Y, Chen X, Gueydan C, Han J (2018) Plasma membrane changes during programmed cell deaths. Cell Res 28:9-21. https://doi.org/10.1038/cr.2017.133

37. Manninen A (2015) Epithelial polarity-generating and integrating signals from the ECM with integrins. Exp Cell Res 334:337-349. https://doi.org/10.1016/j.yexcr.2015.01.003

38. Leight JL, Wozniak MA, Chen S, Lynch ML, Chen CS (2012) Matrix rigidity regulates a switch between TGF- $\beta 1$-induced apoptosis and epithelial-mesenchymal transition. Mol Biol Cell 23:781-791. https://doi.org/10.1091/mbc.E11-06-0537

39. David CJ, Huang YH, Chen M, Su J, Zou Y, Bardeesy N, lacobuzio-Donahue CA, Massagué J (2016) TGF- $\beta$ tumor suppression through a lethal EMT. Cell 164:1015-1030. https://doi.org/10.1016/j.cell.2016.01.009

40. Zhang Y, Alexander PB, Wang XF (2017) TGF- $\beta$ family signaling in the control of cell proliferation and survival. Cold Spring Harb Perspect Biol 9:a022145. https://doi.org/10.1101/cshperspect.a022145

41. Derynck R, Akhurst RJ, Balmain A (2001) TGF-beta signaling in tumor suppression and cancer progression. Nat Genet 29:117-129. https://doi.org/10.1038/ng1001-117

\section{Figures}


a

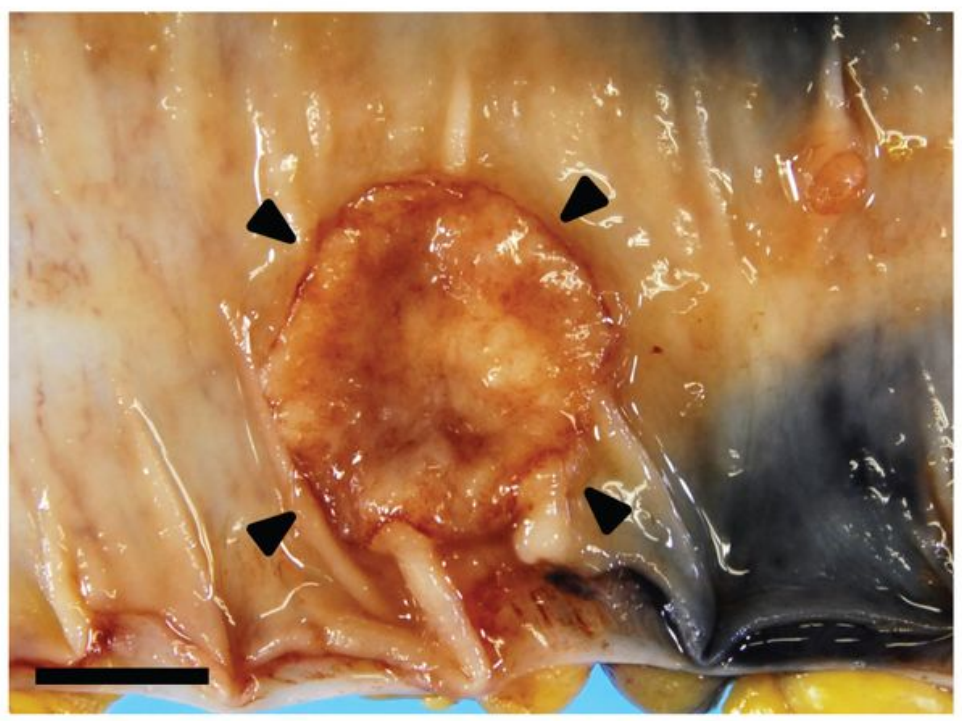

C

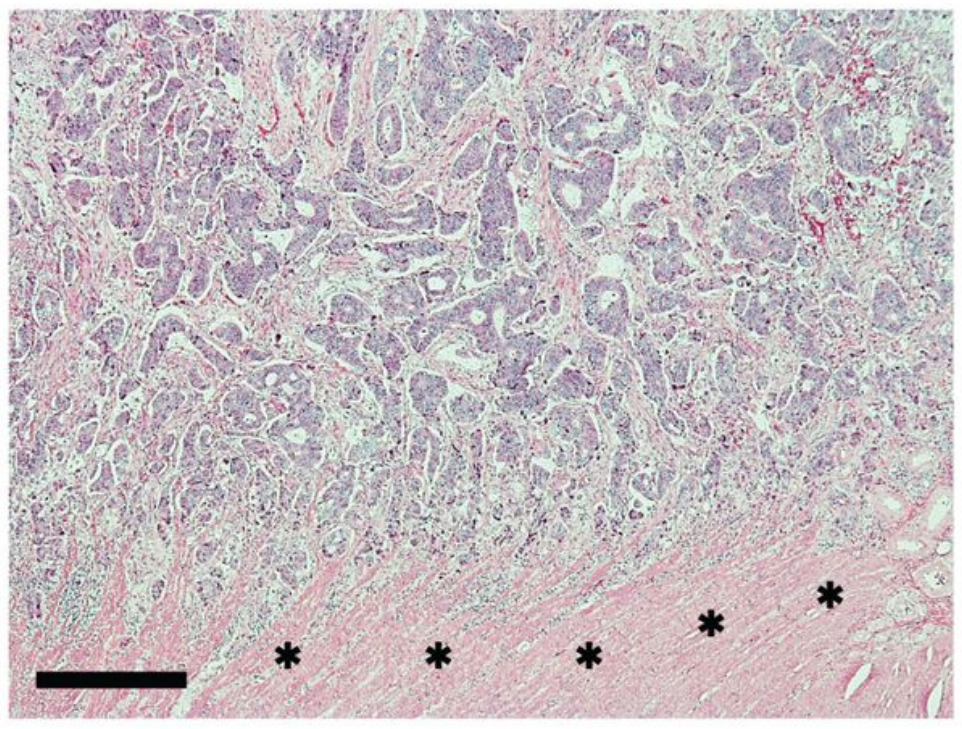

b

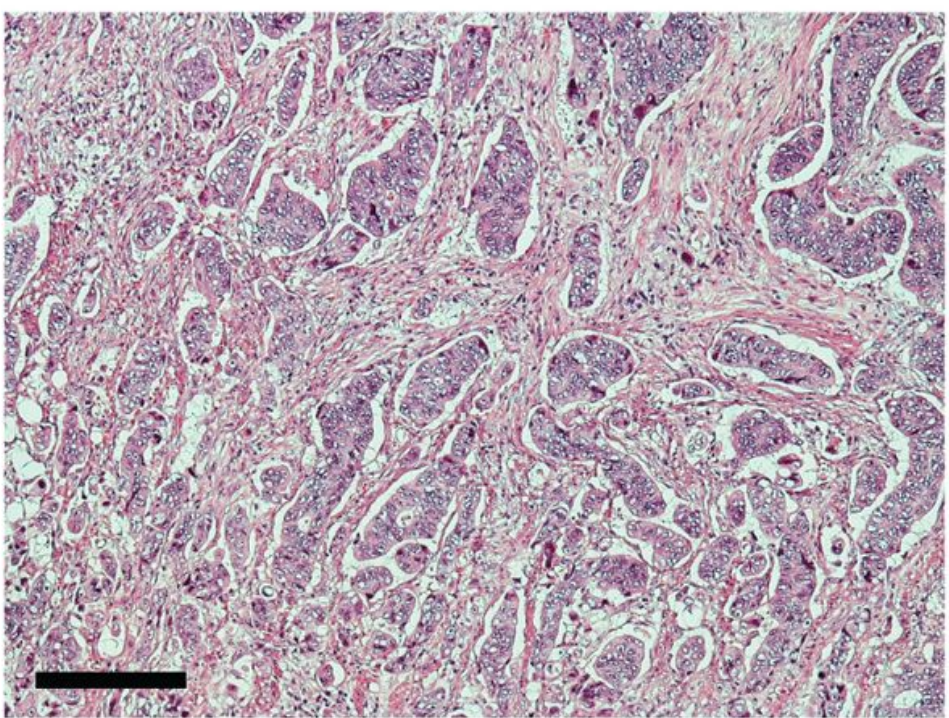

d

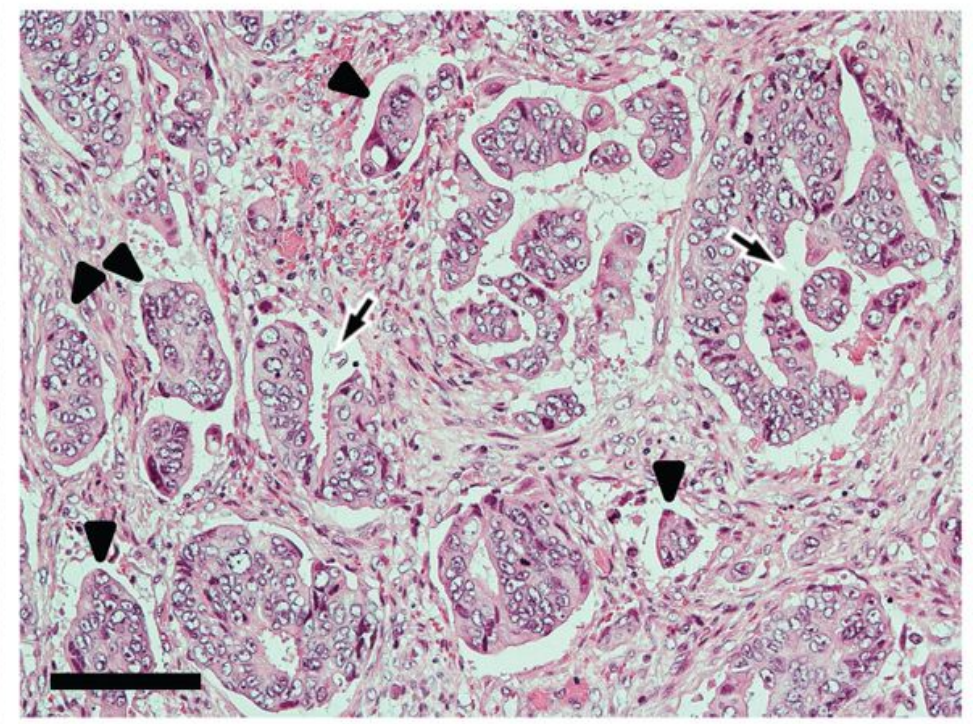

\section{Figure 1}

Routine pathological findings of the tumor of case 1: I (a) Gross view of an ulcerated tumor (surrounded by arrowheads). Scale bar: $1 \mathrm{~cm}$. (b) The tumor consists mainly of poorly differentiated clusters (PDCs) with empty spaces. Hematoxylin and eosin (H\&E) stain. Scale bar: $200 \mu \mathrm{m}$. (c) Granular components with empty spaces decrease toward the invasion front, whereas cell aggregates with poor luminal formation are scattered there. Asterisks indicate colonic muscularis propria. H\&E stain. Scale bar: $400 \mu \mathrm{m}$. (d) In the tumor glands, tumor cell detachment from the stroma and the destruction of a glandular structure are evident (arrows). PDCs (arrowheads) are found near the ruptured tumor gland. H\&E stain. Scale bar: 100 $\mu \mathrm{m}$ 
a

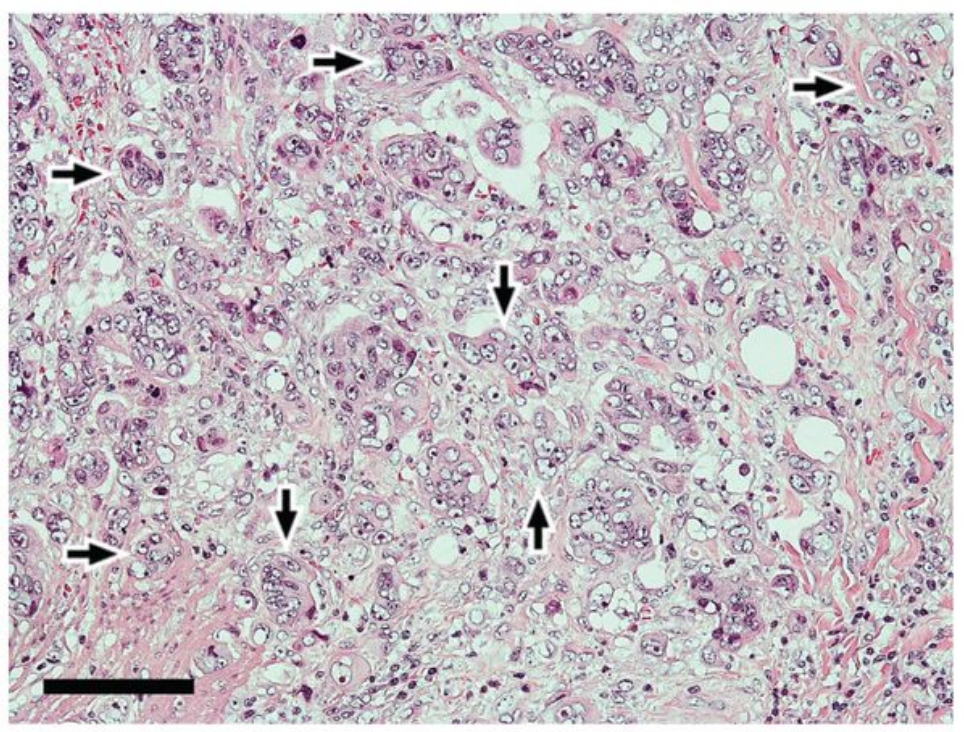

b

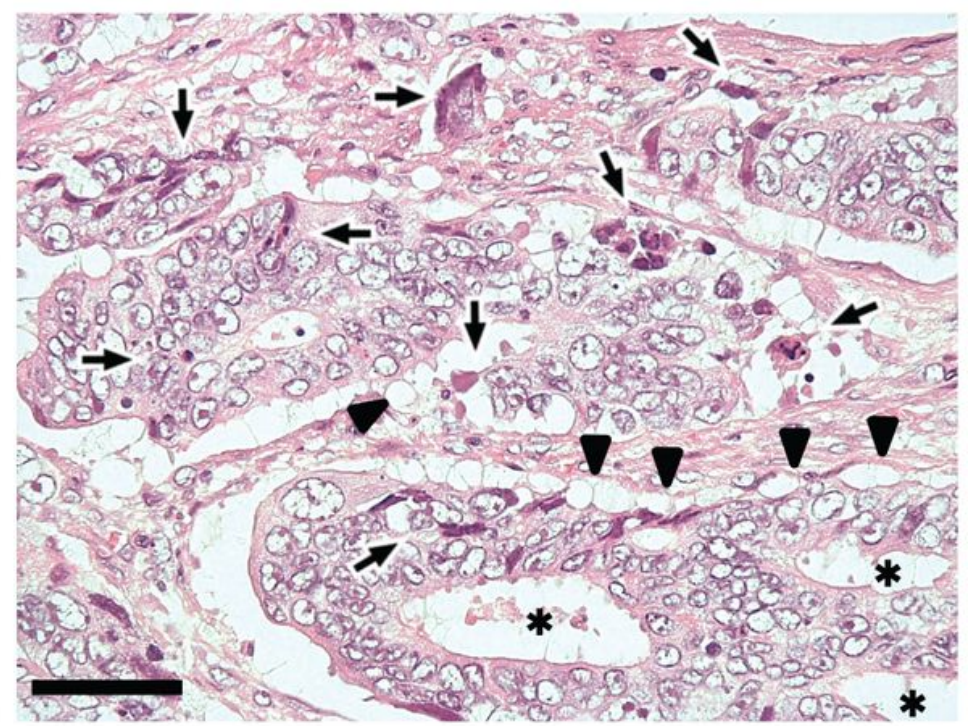

Figure 2

Routine pathological findings of the tumor of case 1: II (a) Magnified image of the invasion front. Tumor buds, composed of ten or less cancer cells (small sized of poorly differentiated clusters) (arrows), are scattered. H\&E stain. Scale bar: $100 \mu \mathrm{m}$. (b) Apoptotic cells and bodies (arrows) are scattered among the tumor cells within the lacunas, some of which have a concentrated vacuole-like appearance (arrowheads). Asterisks indicate lumens. H\&E stain. Scale bar: $50 \mu \mathrm{m}$

a

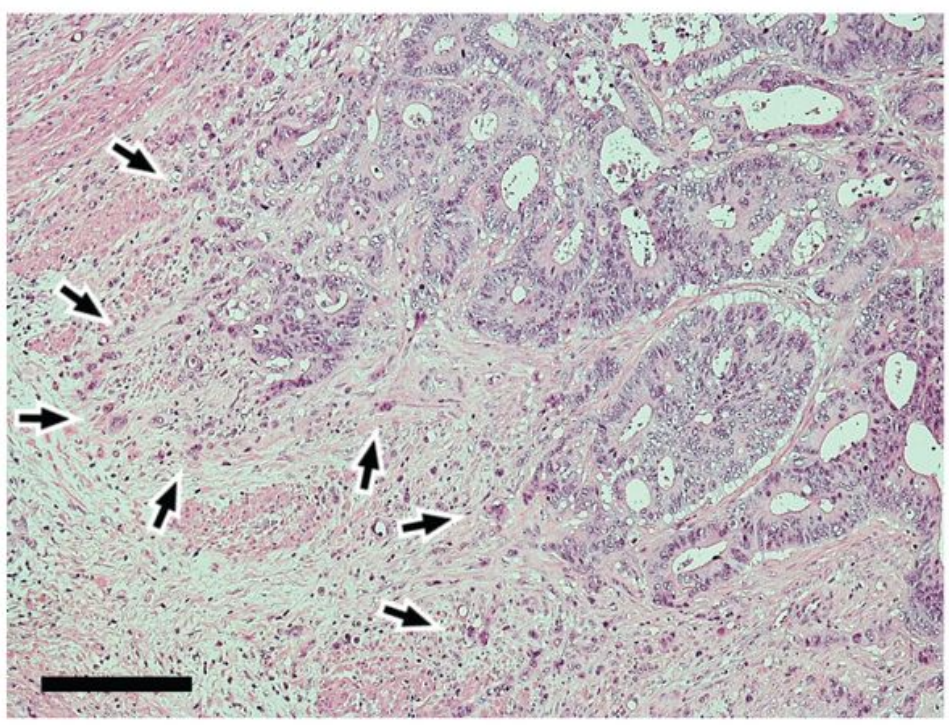

b

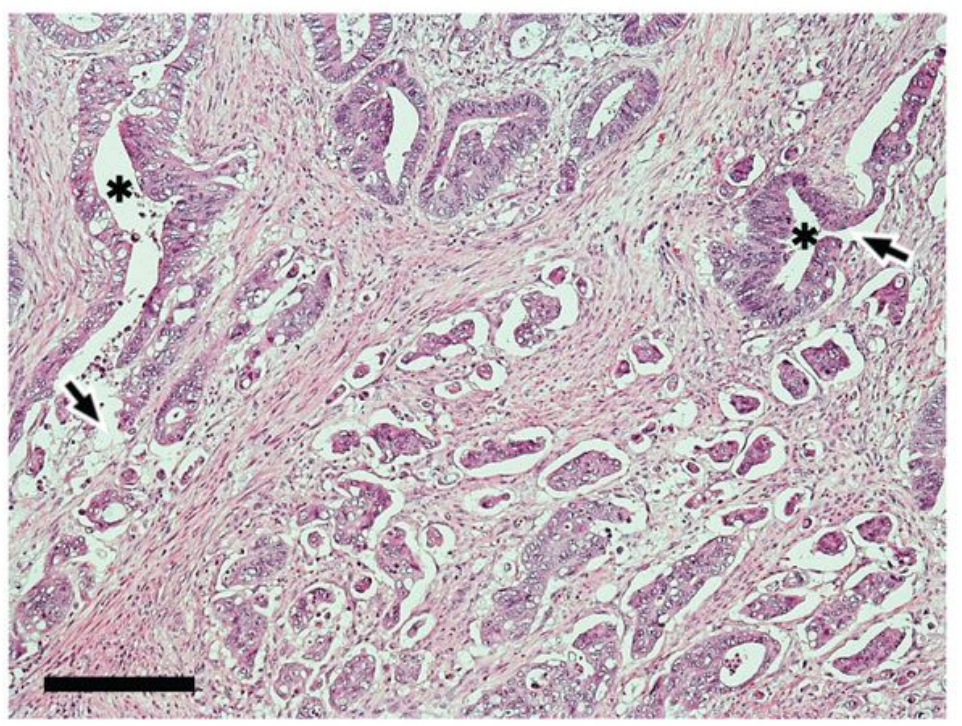

\section{Figure 3}

Representative histology of the case 2 and case 3 tumors (a) Case 2. Tumor budding at the invasion front (arrows) is evident. In tumor glands giving rise to tumor buds, the tumor cells protrude into the stroma in a cord-like appearance. H\&E stain. (b) Case 3. Poorly differentiated clusters and tumor buds are scattered. 
Destruction of the glandular structure is evident in some of the tumor glands (arrows). Asterisks indicate lumens. H\&E stain. Bars: $200 \mu \mathrm{m}$

a

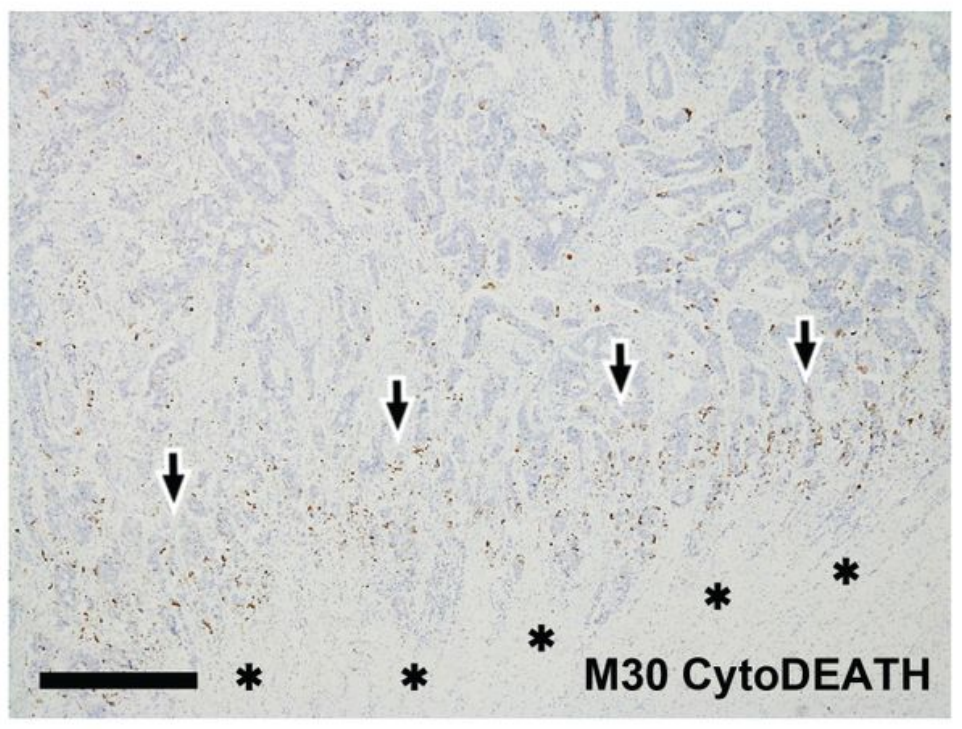

C

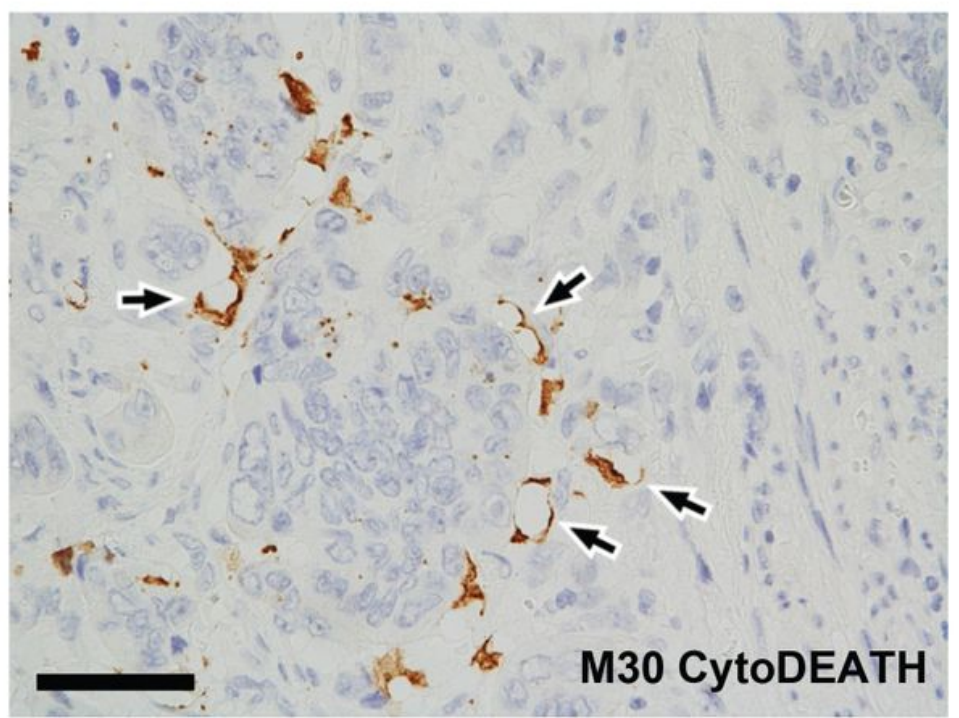

b

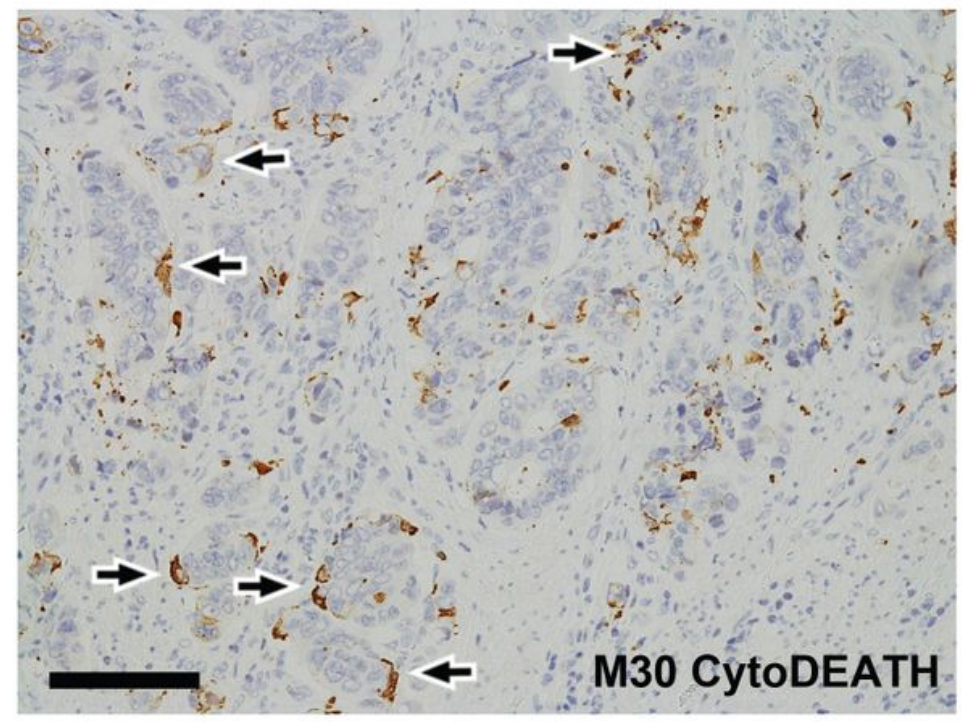

d

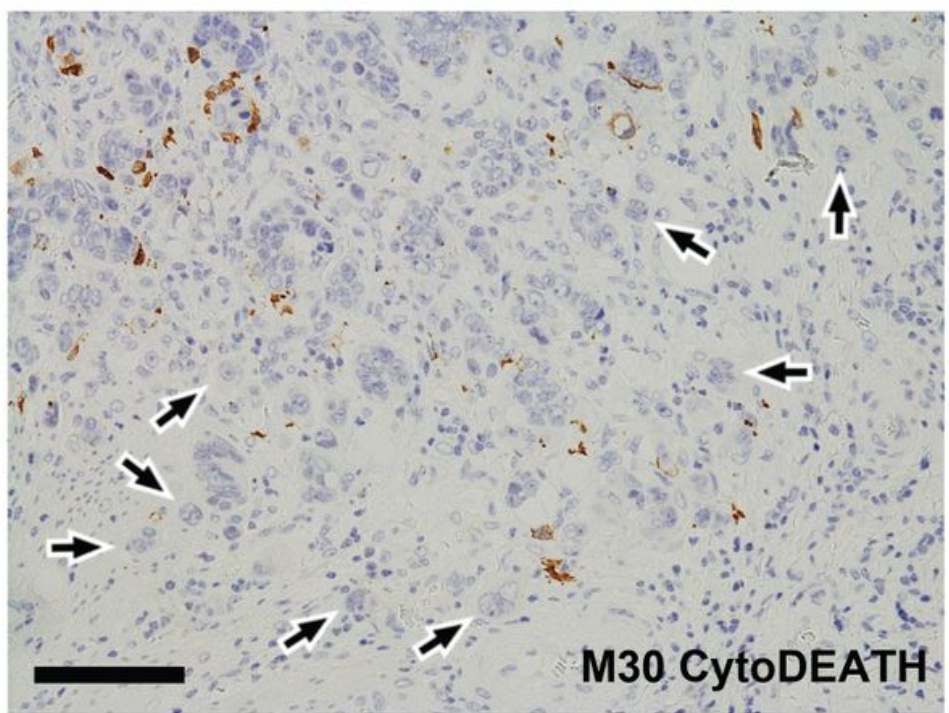

\section{Figure 4}

Immunohistochemistry analyses results for the apoptotic marker M30 CytoDEATH (M30) in the tumor of case 1 (a) M30-positive parts are predominantly distributed in the deep layer of the tumor, in a band-like appearance (arrows). Asterisks indicate colonic muscularis propria. Scale bar: $400 \mu \mathrm{m}$. (b) Positive parts consist of cells and granules located mainly at the periphery of poorly differentiated clusters (PDCs) and tumor glands and within their empty spaces. Arrows indicate apoptotic cells. Scale bar: $100 \mu \mathrm{m}$. (c) Some M30-positive staining within the empty spaces is evident, partially rimming the individual vacuoles (arrows). Scale bar: $50 \mu \mathrm{m}$. (d) Magnified image of the invasion front. M30-positive parts are diminished and barely evident, especially in the tumor buds (arrows). Scale bar: $100 \mu \mathrm{m}$ 

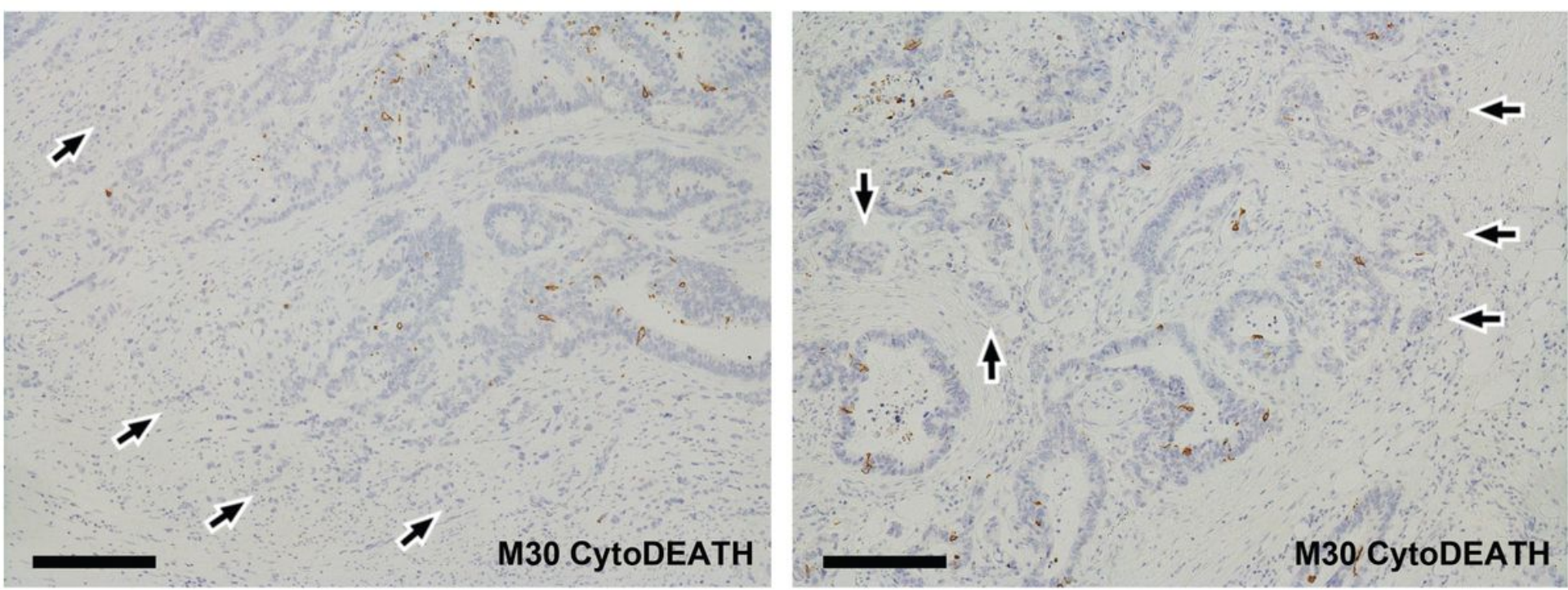

\section{Figure 5}

Immunohistochemistry analyses results for the apoptotic marker M30 in the case 2 and case 3 tumors (a) Case 2. In poorly differentiated clusters (PDCs), tumor buds (arrows), and the protruding tumor cells of tumor glands, only a few positive granules are found. By contrast, M30-positive staining is scattered among the non-protruding tumor cells of the tumor glands. (b) Case 3. M30-positive staining is evident among the tumor cells of the tumor glands, whereas positivity for the protein is barely evident in the PDCs (arrows) and tumor buds. Bars: $200 \mu \mathrm{m}$

a

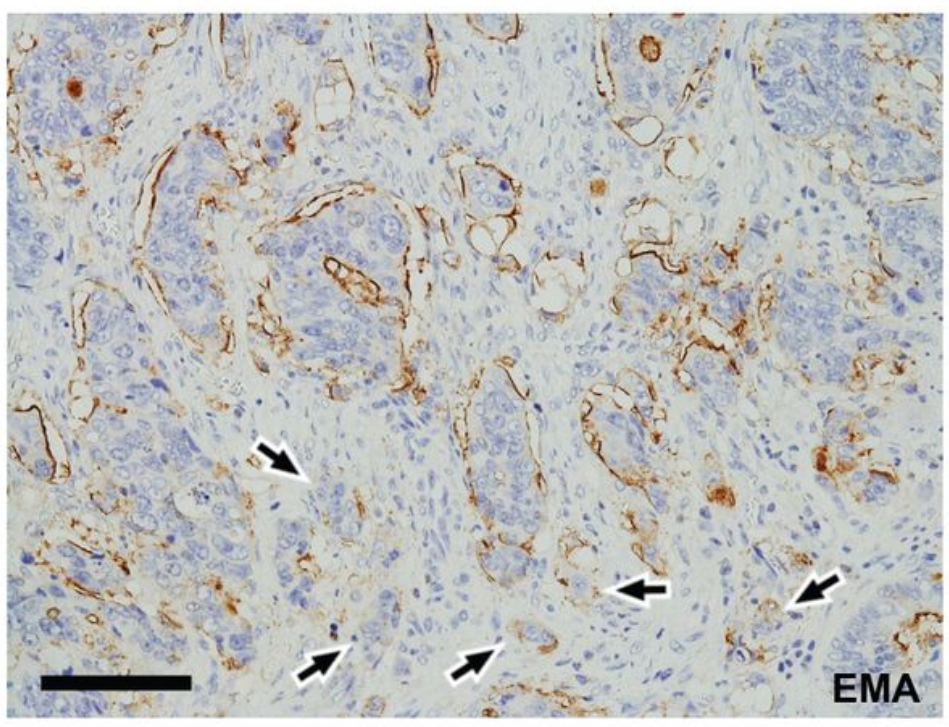

b

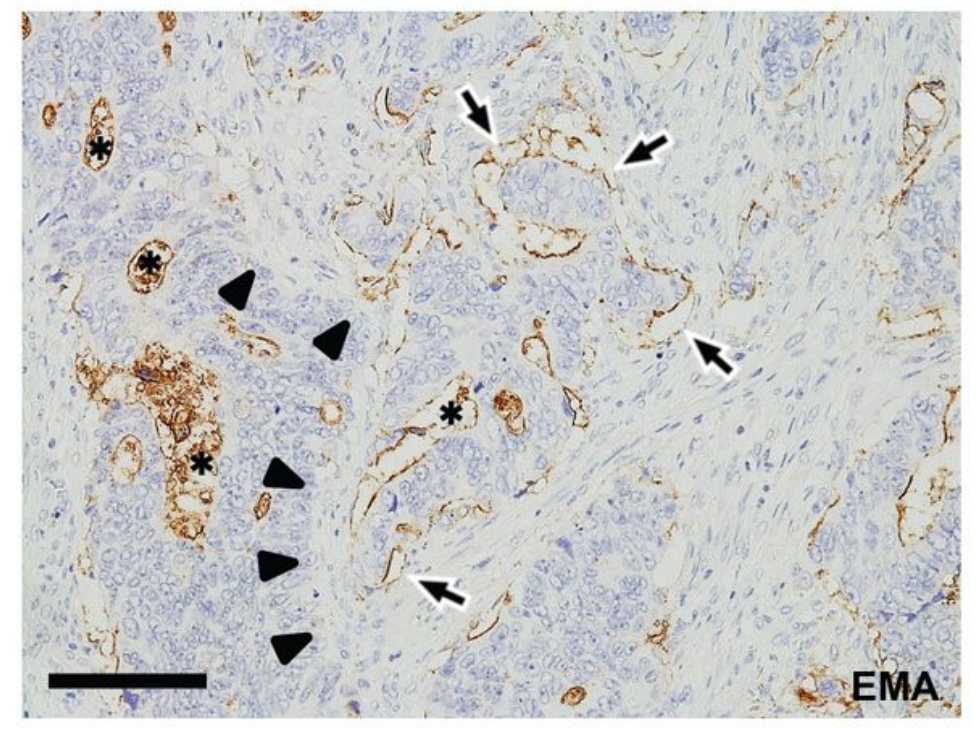

\section{Figure 6}

Immunohistochemistry analyses results for the epithelial membrane antigen in the tumor of case 1 (a) Poorly differentiated clusters (PDCs) show linear positivity for the epithelial membrane antigen at the stroma-facing surfaces, whereas in small PDCs and tumor buds, the linear positivity is weakened 
(arrows). (b) In tumor glands that partially lack contact with the stroma, linear positivity is also found at the stroma-facing surfaces of the detached tumor cells (arrows). Asterisks and arrowheads indicate the lumens and the stroma-facing surfaces of the tumor cells in contact with the stroma, respectively. Bars: $100 \mu \mathrm{m}$

a

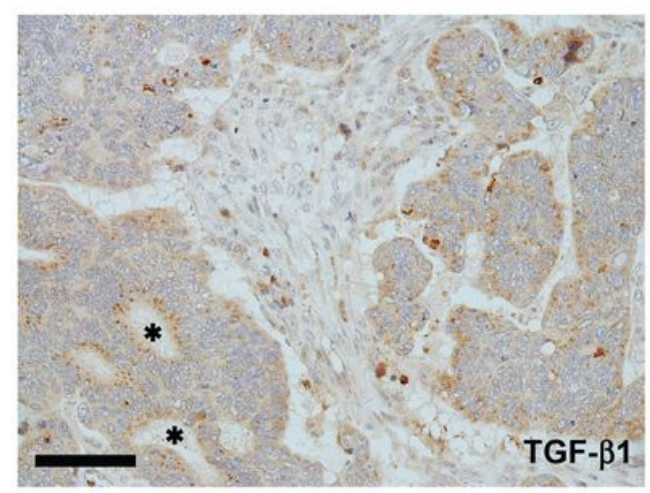

b

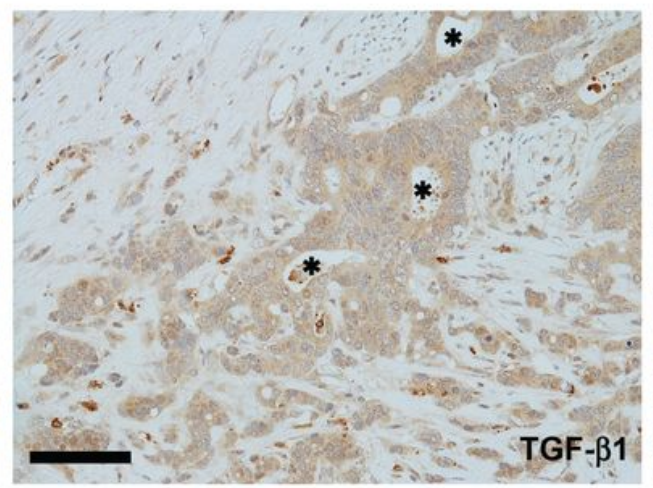

c

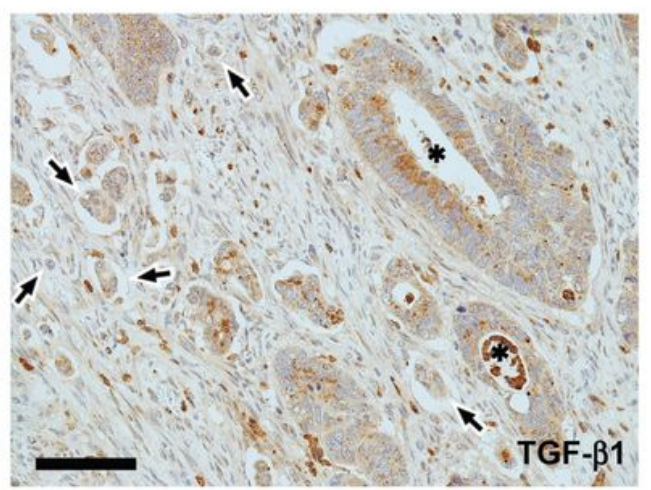

Figure 7

Immunohistochemistry analyses results for transforming growth factor beta 1 in the tumors of all three cases (a) Granular cytoplasmic positivity is evident in both tumor glands with empty spaces and poorly differentiated clusters (PDCs). (b) Faint cytoplasmic positivity is evident in the PDCs, tumor buds, and tumor glands giving rise to PDCs and tumor budding. (c) The results are similar to those of case 1 (a), with small PDCs and tumor buds showing faint positivity (arrows). Inflammatory cells displayed cytoplasmic positivity in all three cases. Asterisks indicate lumens. Bars: $100 \mu \mathrm{m}$

a

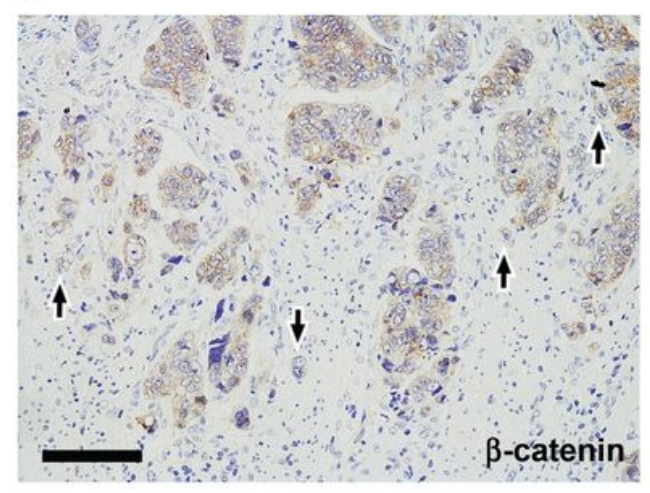

b

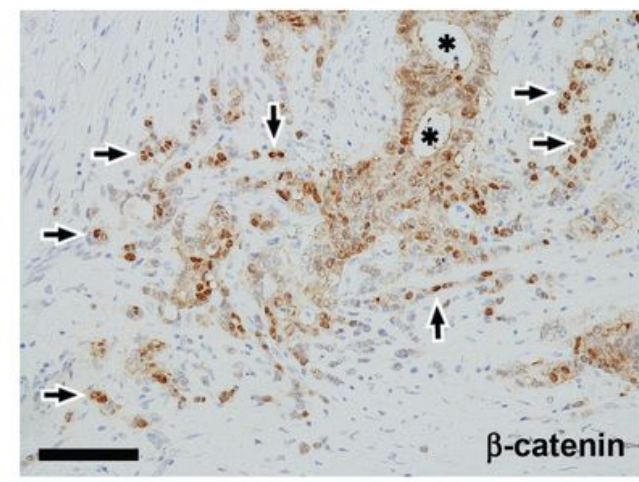

C

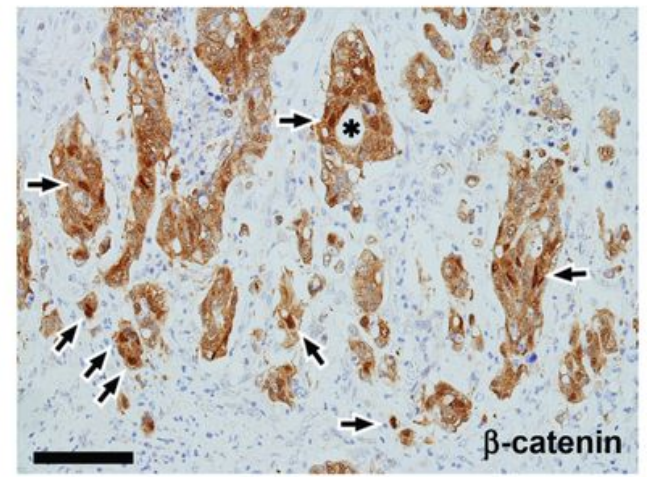

\section{Figure 8}

Immunohistochemistry analyses results for $\beta$-catenin in the tumors of all three cases (a) Poorly differentiated clusters (PDCs) and tumor buds (TBs) show marked reduction in membranous positivity for $\beta$-catenin, without nuclear positivity, and some of the TBs show the loss of stain positivity (arrows). (b) In the PDCs, TBs, and tumor glands (TGs) giving rise to tumor budding and PDCs, the nuclear positivity is scattered. Asterisks and arrows indicate the lumens and both PDCs and TBs, respectively. (c) In the PDCs, TBs, and TGs giving rise to tumor budding and PDCs, diffuse cytoplasmic positivity for $\beta$ - 
catenin is evident, and some of those tumor cells show nuclear positivity. An asterisk and the arrows indicate a lumen and nuclear positivity, respectively. Bars: $100 \mu \mathrm{m}$

\section{Supplementary Files}

This is a list of supplementary files associated with this preprint. Click to download.

- FCAraiARAKEJ35RevisedCareChecklist.pdf 